\title{
BMJ Open Thyroid dysfunction and electrocardiographic changes in subjects without arrhythmias: a cross-sectional study of primary healthcare subjects from Copenhagen
}

To cite: Tayal B, Graff C, Selmer C, et al. Thyroid dysfunction and electrocardiographic changes in subjects without arrhythmias: a cross-sectional study of primary healthcare subjects from Copenhagen. BMJ Open 2019:9:e023854. doi:10.1136/ bmjopen-2018-023854

- Prepublication history and additional material for this paper are available online. To view these files, please visit the journal online (http://dx.doi. org/10.1136/bmjopen-2018023854).

Received 26 April 2018 Revised 4 April 2019 Accepted 10 April 2019
Check for updates

(c) Author(s) (or their employer(s)) 2019. Re-use permitted under CC BY-NC. No commercial re-use. See rights and permissions. Published by BMJ.

For numbered affiliations see end of article.

Correspondence to Dr Bhupendar Tayal; bhupendar.tayal@gmail.com

Bhupendar Tayal, ${ }^{1}$ Claus Graff, ${ }^{2}$ Christian Selmer, ${ }^{3}$ Kristian Hay Kragholm, ${ }^{4,5}$ Magnus Kihlstrom, ${ }^{6}$ Jonas Bille Nielsen, ${ }^{7}$ Anne-Marie Schjerning Olsen, ${ }^{6}$ Adrian Holger Pietersen, ${ }^{8}$ Anders G Holst, ${ }^{9}$ Peter Søgaard, ${ }^{10}$ Christine Benn Christiansen, ${ }^{11}$ Jens Faber, ${ }^{3,12}$ Gunnar Hilmar Gislason, ${ }^{12,13}$ Christian Torp-Pedersen, ${ }^{10,14}$ Steen M Hansen ${ }^{15}$

\section{ABSTRACT}

Objective The objective of the present study was to investigate associations of both overt and subclinical thyroid dysfunction with common ECG parameters in a large primary healthcare population.

Design Cross-sectional study.

Setting and participants The study population comprised of primary healthcare patients in Copenhagen, Denmark, who had a thyroid function test and an ECG recorded within 7 days of each other between 2001 and 2011.

Data sources The Danish National Patient Registry was used to collect information regarding baseline characteristics and important comorbidities.

Outcome measure and study groups Common ECG parameters were determined using Marquette 12SL software and were compared between the study groups. The study population was divided into five groups based on their thyroid status. Euthyroid subjects served as the reference group in all analyses.

Results A total of 132707 patients (age $52 \pm 17$ years; $50 \%$ female) were included. Hyperthyroidism was significantly associated with higher heart rate and prolonged QTc interval with significant interaction with age $(p<0.009)$ and sex $(p<0.001)$. These associations were less pronounced for patients with higher age. Subclinical hyperthyroidism was associated with higher heart rate among females, and a similar trend was observed among males. Hypothyroidism was associated with slower heart rate and shorter QTC but only in women. Moreover, longer P-wave duration, longer PR interval and low voltage were observed in patients with both subclinical and overt hypothyroidism. However, the presence of low voltage was less pronounced with higher age $(p=0.001)$.

Conclusion Both overt and subclinical thyroid disorders were associated with significant changes in important ECG parameters. Age and gender have significant impact on the association of thyroid dysfunction particularly on heart rate and QTC interval.
Strengths and limitations of this study

This is the largest study $(n=132707)$ so far investigating the effect of thyroid dysfunction on the ECG.

- Study subjects are categorised into clinical groups of thyroid dysfunctions making the interpretation and use of the study results easier in routine clinics.

- The study population is from the greater Copenhagen area that consists mainly of Caucasian people; therefore, extrapolation of the findings to other ethnic groups should be done carefully.

- Since no uniform selection criteria were applied and subjects were referred for thyroid function test and ECG based on the discretion of the general practitioner, some selection bias cannot be ruled out.

\section{INTRODUCTION}

Overt and subclinical thyroid dysfunction is frequently observed in the general population, especially in the elderly, ${ }^{12}$ and is closely linked with the cardiovascular system and affects the haemodynamics, cardiac mass, cardiac contractility and autonomic control of the cardiovascular system. ${ }^{3}$ Thyroid dysfunction has been widely demonstrated to be associated with various cardiovascular disorders and is associated with increased all-cause mortality, increased cardiovascular mortality as well as morbidity. ${ }^{4-6}$ Subclinical thyroid dysfunction is defined as abnormal thyroid-stimulating hormone (TSH) values with thyroxine (T4) and triiodothyronine (T3) levels within the normal range. Even these minor changes in the thyroid function in subclinical thyroid dysfunction are associated with various kinds of cardiovascular 


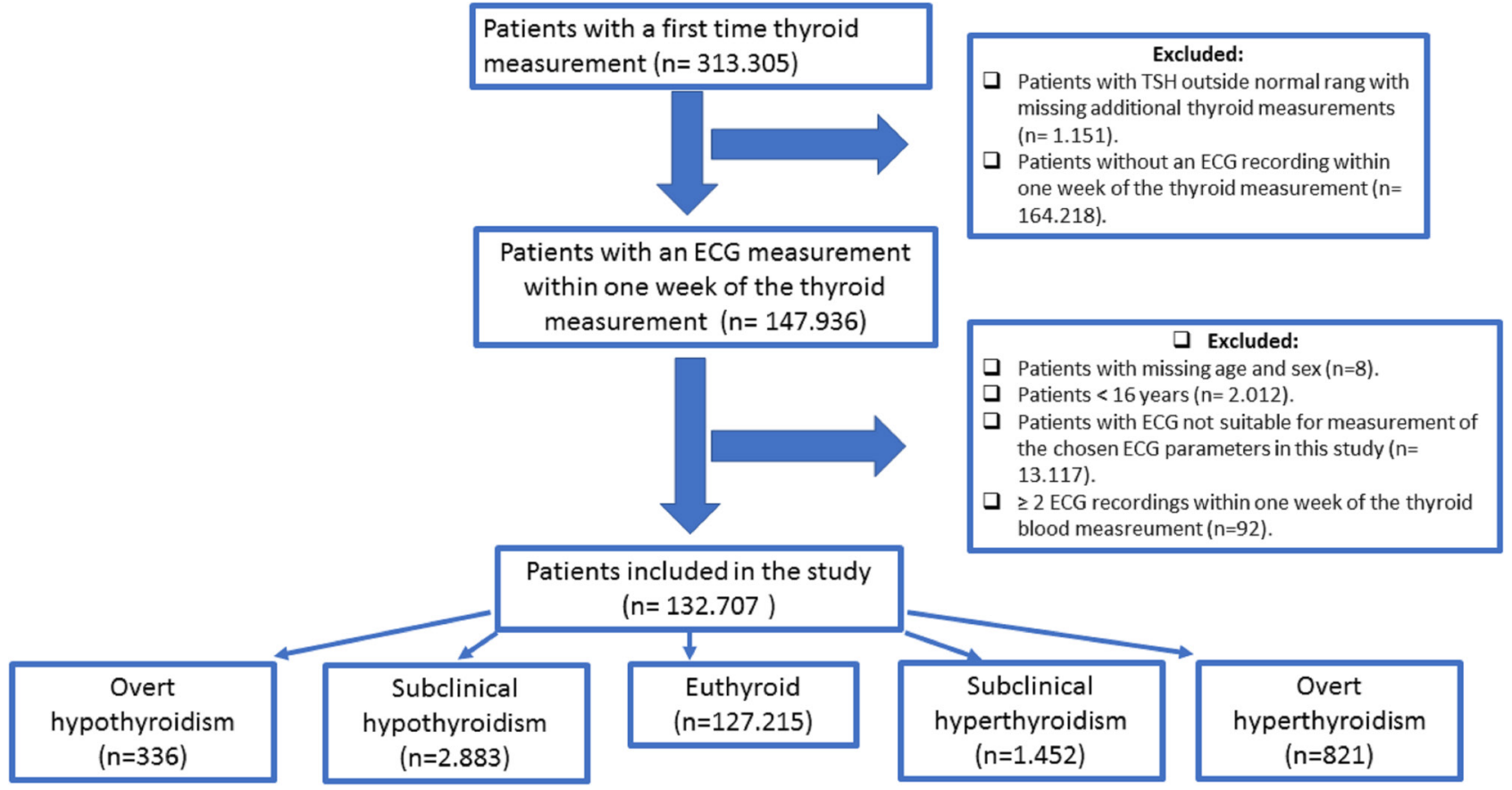

Figure 1 Patient inclusion flow chart. Flow-chart showing the details of the inclusion process of patients for the study. TSH, thyroid-stimulating hormone.

disorders, such as heart failure, ${ }^{7}$ atrial fibrillation ${ }^{48}$ and coronary artery disease. ${ }^{9}$

Various ECG changes are associated to the spectrum of thyroid dysfunction, ${ }^{1011}$ and they are potentially critical as even subtle ECG changes have prognostic importance. ${ }^{12} 13$ Important ECG changes described in hypothyroidism are sinus bradycardia, prolonged QTc interval, changes in the morphology of the T-wave, QRS duration and low voltage..$^{10} 111415$ Similarly, hyperthyroidism is associated with increased incidence of atrial arrhythmias and changes in the QT interval. ${ }^{411617}$ However, most of these conclusions of ECG changes are based on studies with small-size population. Thus far, only two studies have investigated the ECG changes that occur in thyroid dysfunction in

\begin{tabular}{|c|c|c|c|}
\hline $\begin{array}{l}\text { Thyroid } \\
\text { dysfunction } \\
\text { definitions }\end{array}$ & TSH & FT4 & T4T \\
\hline $\begin{array}{l}\text { Overt } \\
\text { hyperthyroidism }\end{array}$ & $<0.2 \mathrm{mU} / \mathrm{L}$ & $>22 \mathrm{pmol} / \mathrm{L}$ & $>140 \mathrm{nmol} / \mathrm{L}$ \\
\hline $\begin{array}{l}\text { Subclinical } \\
\text { hyperthyroidism }\end{array}$ & $<0.2 \mathrm{mU} / \mathrm{L}$ & 9-22 pmol/L & $\begin{array}{l}60- \\
140 \mathrm{nmol} / \mathrm{L}\end{array}$ \\
\hline Euthyroidism & $0.2-5.0 \mathrm{mU} / \mathrm{L}$ & 9-22 pmol/L & $\begin{array}{l}60- \\
140 \mathrm{nmol} / \mathrm{L}\end{array}$ \\
\hline $\begin{array}{l}\text { Subclinical } \\
\text { hypothyroidism }\end{array}$ & $>5.0 \mathrm{mU} / \mathrm{L}$ & 9-22 pmol/L & $\begin{array}{l}60- \\
140 \mathrm{nmol} / \mathrm{L}\end{array}$ \\
\hline $\begin{array}{l}\text { Overt } \\
\text { hypothyroidism }\end{array}$ & $>5.0 \mathrm{mU} / \mathrm{L}$ & $<9 \mathrm{pmol} / \mathrm{L}$ & $<60 \mathrm{nmol} / \mathrm{L}$ \\
\hline
\end{tabular}

FT4, free thyroxine; T4T, total thyroxine; TSH, thyroidstimulating hormone. moderately large-scale population studies. ${ }^{10}{ }^{17}$ However, instead of assigning the population into thyroid dysfunction group, both these studies investigated the direct association of either TSH or T4 with the ECG parameters, which makes it difficult to interpret in a clinical context. The aim of this study was to investigate associations of overt and subclinical stages of thyroid dysfunction to important ECG parameter changes in a large primary care population.

\section{METHODS}

\section{Study population}

The study population consisted of primary care patients, who were referred for thyroid function testing and digital ECG recording at the Copenhagen General Practitioners Laboratory (CGPL) between 2001 and 2011. The CGPL is a biochemistry laboratory, to which general practitioners refer patients for investigations from the greater Copenhagen area in Denmark. The centralised laboratory ensures standardised procedures for the clinical tests. Data on serum TSH, free T4 (FT4) and total T4 were determined by the commercially available ADVIA Centaur equipment (Bayer/Siemens, Tarrytown, New York, USA). The same ADVIA centaur system from Siemens was used throughout the study period, and all assays were routinely subjected to external control for reliability. The intraassay coefficient of variation: $<10 \%$ for all (TSH, FT 4 and total T4). Subjects were included if they had a thyroid function test (TFT) and a concomitant ECG recorded within duration of \pm 7 days. Subjects with age $<16$ years or having an ECG unsuitable for measurement of chosen ECG parameters were excluded (figure 1). 
Table 2 Baseline characteristics of study cohort

\begin{tabular}{|c|c|c|c|c|c|}
\hline Variable & $\begin{array}{l}\text { Overt } \\
\text { hyperthyroidism } \\
(\mathrm{n}=821)\end{array}$ & $\begin{array}{l}\text { Subclinical } \\
\text { hyperthyroidism } \\
\text { (n=1452) }\end{array}$ & $\begin{array}{l}\text { Euthyroidism } \\
(n=127215)\end{array}$ & $\begin{array}{l}\text { Subclinical } \\
\text { hypothyroidism } \\
\text { (n=2883) }\end{array}$ & $\begin{array}{l}\text { Overt } \\
\text { hypothyroidism } \\
(n=336)\end{array}$ \\
\hline Age (years) & $54.0(18.2)$ & $64.3(16.4)$ & $52.2(16.8)$ & $58.4(16.7)$ & $57.7(16.1)$ \\
\hline Sex (men) & 177 (21.6) & $386(26.6)$ & $64867(51.0)$ & $692(24.0)$ & $89(26.5)$ \\
\hline \multicolumn{6}{|l|}{ Thyroid function status } \\
\hline TSH (mU/L) & $0.0(0.0)$ & $0.1(0.1)$ & $1.6(0.9)$ & $9.5(8.3)$ & $64.3(43.0)$ \\
\hline Free T4 (pmol/L) & $42.2(23.6)$ & $17.2(2.6)$ & $15.4(2.3)$ & $13.4(2.2)$ & $6.1(1.9)$ \\
\hline Total T4 (pmol/L) & $200.0(63.0)$ & $111.2(19.4)$ & $105.5(21.7)$ & $91.7(17.9)$ & $39.7(16.9)$ \\
\hline \multicolumn{6}{|l|}{ Comorbidity (\%) } \\
\hline PVD & $9(1.1)$ & $24(1.7)$ & $992(0.8)$ & $28(1.0)$ & $\leq 3^{*}$ \\
\hline Heart failure & $12(1.5)$ & $22(1.5)$ & $1012(0.8)$ & $37(1.3)$ & $4(1.2)$ \\
\hline Ischaemic heart disease & $18(2.2)$ & $60(4.1)$ & 3295 (2.6) & $88(3.1)$ & $12(3.6)$ \\
\hline MI & $10(1.2)$ & $22(1.5)$ & $1238(1.0)$ & $36(1.2)$ & $4(1.2)$ \\
\hline $\mathrm{AF}$ & $10(1.2)$ & $25(1.7)$ & $1057(0.8)$ & $32(1.1)$ & $\leq 3$ \\
\hline Arrhythmias & $9(1.1)$ & $13(0.9)$ & $1029(0.8)$ & $32(1.1)$ & $\leq 3$ \\
\hline CVD & $15(1.8)$ & $64(4.4)$ & $2281(1.8)$ & $51(1.8)$ & $10(3.0)$ \\
\hline Malignancy & $38(4.6)$ & $59(4.1)$ & 3301 (2.6) & $113(3.9)$ & $13(3.9)$ \\
\hline Chronic renal failure & $\leq 3$ & $\leq 3$ & $109(0.1)$ & $4(0.1)$ & $0(0.0)$ \\
\hline Diabetes & $32(3.9)$ & $69(4.8)$ & $3663(2.9)$ & $87(3.0)$ & $10(3.0)$ \\
\hline COPD & $23(2.8)$ & $54(3.7)$ & $2089(1.6)$ & $52(1.8)$ & $8(2.4)$ \\
\hline Rheumatic disease & $6(0.7)$ & $16(1.1)$ & $686(0.5)$ & $30(1.0)$ & $\leq 3$ \\
\hline \multicolumn{6}{|l|}{ Drugs (\%) } \\
\hline Lithium & $0(0.0)$ & $\leq 3$ & $210(0.2)$ & $9(0.3)$ & $\leq 3$ \\
\hline Glucocorticoids & $18(2.2)$ & $56(3.9)$ & $2058(1.6)$ & $48(1.7)$ & $7(2.1)$ \\
\hline QTc-prolonging drugs & 108 (13.2) & 270 (18.6) & $18249(14.3)$ & 447 (15.5) & $51(15.2)$ \\
\hline Sotalol & $\leq 3$ & $\leq 3$ & $204(0.2)$ & $5(0.2)$ & $0(0.0)$ \\
\hline Digoxin & $9(1.1)$ & $21(1.4)$ & $592(0.5)$ & $27(0.9)$ & $\leq 3$ \\
\hline Amiodarone & $\leq 3$ & $\leq 3$ & $14(0.0)$ & $\leq 3$ & $0(0.0)$ \\
\hline Warfarin & $4(0.5)$ & $11(0.8)$ & $558(0.4)$ & $12(0.4)$ & $0(0.0)$ \\
\hline Beta-blockers & $67(8.2)$ & $112(7.7)$ & $7543(5.9)$ & $221(7.7)$ & $15(4.5)$ \\
\hline Calcium antagonist & $33(4.0)$ & $137(9.4)$ & $7528(5.9)$ & $222(7.7)$ & $19(5.7)$ \\
\hline ACE inhibitors or ARB & $47(5.7)$ & $174(12.0)$ & $10823(8.5)$ & $263(9.1)$ & $33(9.8)$ \\
\hline Thiazides & $74(9.0)$ & $209(14.4)$ & $9633(7.6)$ & $328(11.4)$ & $41(12.2)$ \\
\hline Spironolactone & $5(0.6)$ & $13(0.9)$ & $577(0.5)$ & $20(0.7)$ & $\leq 3$ \\
\hline Loop diuretics & $38(4.6)$ & $100(6.9)$ & 3091 (2.4) & $131(4.5)$ & $11(3.3)$ \\
\hline
\end{tabular}

*Numbers less than 3 are not reported.

AF, atrial fibrillation or atrial flutter; ARB, angiotensin II receptor blocker; COPD, chronic obstructive pulmonary disease; CVD, cardiovascular disease; MI, myocardial infarction; PVD, peripheral vascular disease; T4, thyroxine; TSH, thyroid-stimulating hormone.

The study population's baseline characteristics, including comorbidities, were obtained from the Danish National Patient Registry that contains information on outpatient and hospital contacts where every diagnosisprimary and secondary—are coded based on the WHO's International Classification of Diseases (ICD).$^{18}$ The diagnoses obtained from this registry has previously been validated and has a high positive predictive value. ${ }^{19}$ ICD codes used for the classification of various comorbidities are provided in online supplementary appendix A.

The Information regarding concomitant medication therapy was obtained from The Danish Register of Medicinal Product Statistics (online supplementary appendix B), which holds data on all prescriptions from pharmacies in Denmark coded according to the international Anatomical Therapeutic Chemical 


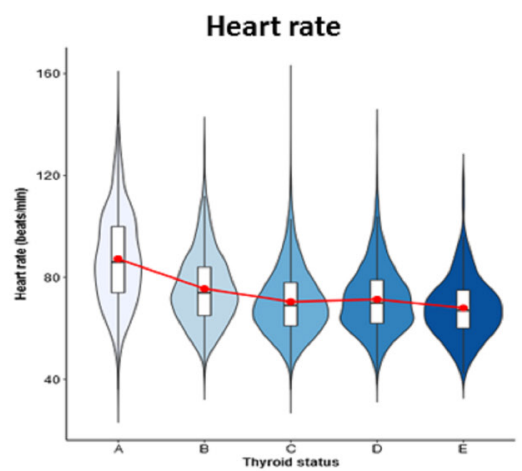

P wave Duration

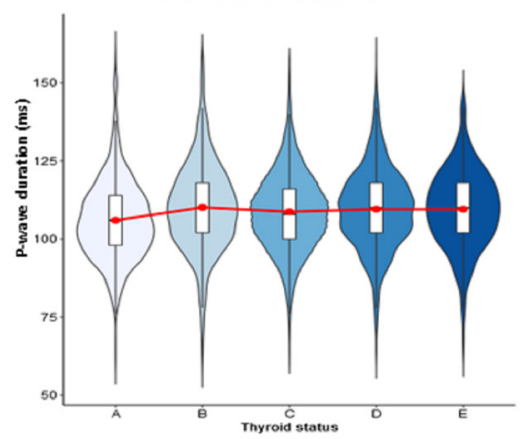

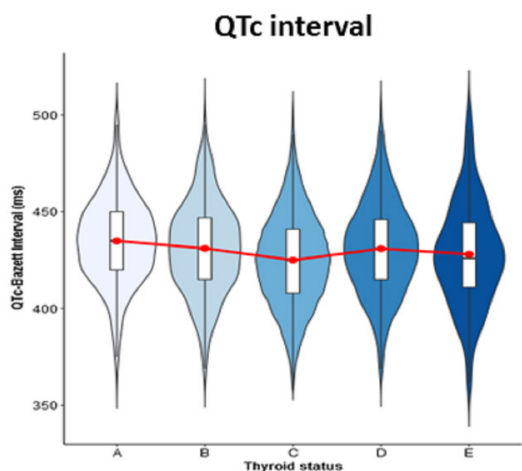

PR interval

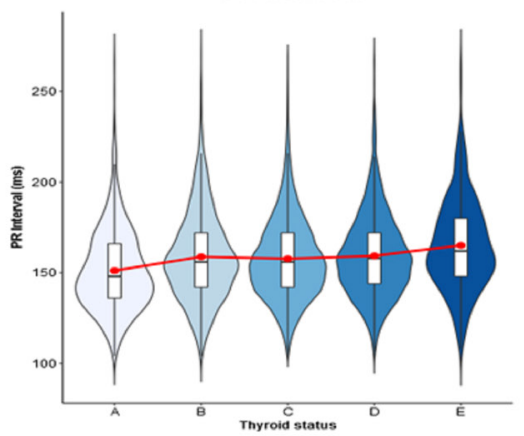

Thyroid status

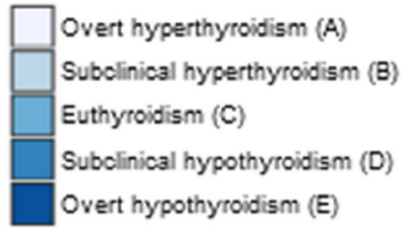

QRS duration

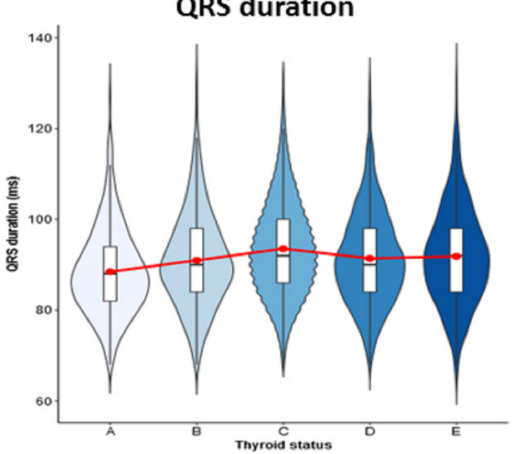

Figure 2 Mean ECG changes with thyroid dysfunction. Violin plots demonstrating the changes in the ECG parameters with thyroid dysfunction. The white box in the middle indicates the mean value and the red line indicates the trend with the changes in the thyroid status. The central blue area demonstrates the distribution of the individual parameters.

classification. $^{20}$ All medication reported to influence thyroid function ${ }^{5}$ and ECG findings ${ }^{12} 2122$ were included in the present study.

\section{Study groups}

Patients were divided into five study groups based on $\mathrm{TSH}$, free T3 and free T4 levels summarised in table 1. T3-thyrotoxicosis was defined as low TSH with normal T4 but elevated T3.

\section{Electrocardiography}

At the CGPL, digital ECGs were recorded by trained technicians according to a standardised protocol and were stored in the MUSE Cardiology Information system (GE Healthcare, Wauwatosa, Wisconsin, USA). The digital ECGs were processed using version 21 of the Marquette 12SL algorithm. Using the 12SL algorithm, the following ECG parameters were measured: P-wave duration, PR interval, QRS duration and QTc interval (Bazett's formula, $\left.\mathrm{QTc}_{\mathrm{Baz}}=\mathrm{QT}(\mathrm{ms}) /[\mathrm{RR} \text { interval }(\mathrm{ms}) / 1000]^{1 / 2}\right)$. P-wave duration, PR interval and QRS duration were adjusted for the heart rate. Low voltage was defined as a net QRS voltage $<500 \mu \mathrm{V}$ in all limb leads and/or $<1000$ $\mu \mathrm{V}$ in precordial leads. We have previously described in detail about how the 12SL software is used to measure the various ECG parameters as well as validated these measurements. ${ }^{12}$

Only subjects having sinus rhythm on the analysed ECG were included; those with any kind of tachyarrhythmiasupraventricular or ventricular-were excluded to study the influence of thyroid dysfunction on ECG measurements. Furthermore, subjects were excluded if they had any of the following ECG findings: all atrio-ventricular (AV) blocks except first degree blocks, pace rhythms, bundle branch blocks (QRS interval $>120 \mathrm{~ms}$ ), multiple premature ventricular complexes or supraventricular complexes, delta waves, poor quality ECGs and intervals of interest below the 0.25 th percentile and above the 99.75th percentile of the study population. This filtering step has previously been validated to exclude ECGs unsuitable for measurement ${ }^{12122}$ (figure 1).

\section{Statistical analyses}

Continuous variables were presented as their mean $\pm \mathrm{SD}$ and compared using analysis of variance, and categorical variables were presented as counts and percentages and compared using $\chi^{2}$ test. For all comparison purposes, the euthyroid group was used as the reference group. Multiple linear regression analysis was performed using important ECG parameters-P-wave duration, PR interval, QRS duration, QTc interval (Bazett) and heart rate-as dependent variables and the five thyroid status groups as independent categorical variables. All models were adjusted for age and sex. In addition, P-wave duration, PR interval and QRS duration were all adjusted for heart rate. All ECG parameters were normally distributed and model assumptions were fulfilled. Multiple logistic regression analysis was used to assess the association between thyroid status and low voltage on ECG adjusting for age, sex and heart rate. For each analysis, tests for interaction were performed. An interaction was considered significant 
Women

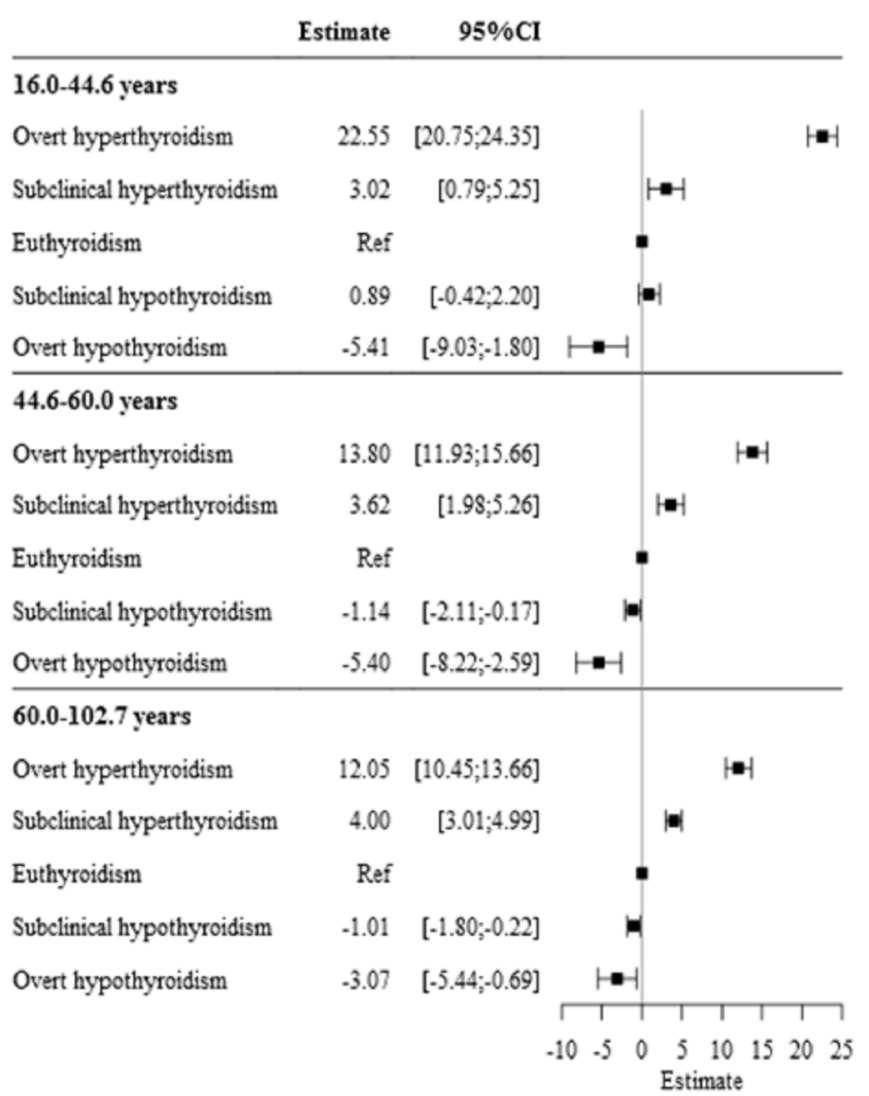

Men

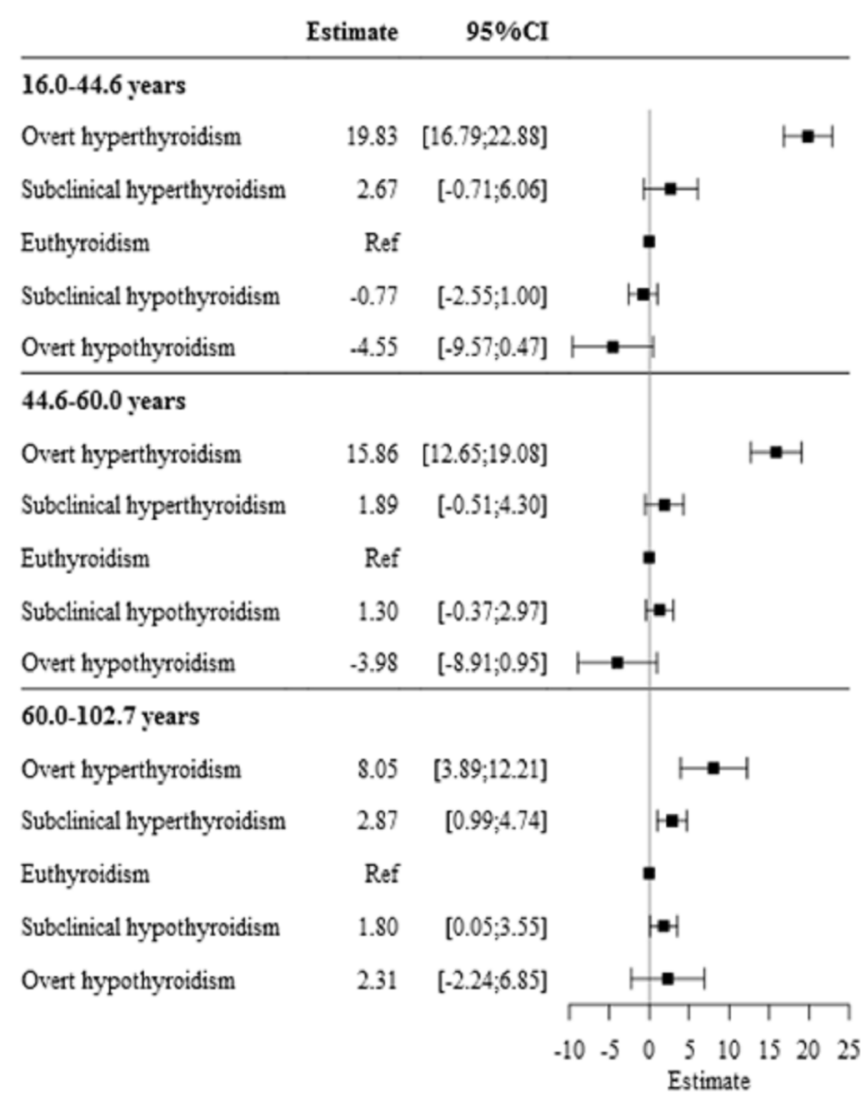

Figure 3 Changes in heart rate with thyroid dysfunction by gender and age. Regression plots showing the changes in the heart rate (beats/min) with thyroid disorders based on age groups and gender. Euthyroidism is the reference group.

with a $\mathrm{p}$ value of less than 0.01 . When an interaction with age was identified, population was stratified into groups using the tertile values as cut-offs (age groups: 16.0-44.6 years, $44.6-60.0$ years and $60.0-102.7$ years).

We further performed sensitivity analyses, in which we excluded cardiac comorbidities (cardiac arrhythmias, ischaemic heart disease and congestive heart failure), as well as cardiac medications that are known to impact ECG parameters, such as QTc-prolonging drugs, class I and III antiarrhythmic drugs, digoxin, beta-blockers. The impact of TSH levels on heart rate and QTc interval was examined in additional analyses where TSH was included as a continuous variable in linear regression models using b-splines. These analyses were stratified according to age and sex as mentioned above. A two-tailed $p$ value $<0.05$ was considered statistically significant in all analyses. Data management and analyses were performed using SAS V.9 and R V.3.4.1.

\section{Patients and public involvement}

There was no active patient or public involvement in the current study.

\section{RESULTS}

A total of 147936 subjects were identified from the CGPL database that had a TFT and an ECG recorded within 7 days of each other between 2001 and 2011. After exclusion, 132707 subjects $(90 \%)$ were included for further analyses. Of these, $827(0.6 \%)$ had overt hyperthyroidism, $1452(1.1 \%)$ had subclinical hyperthyroidism, $2883(2.1 \%)$ had subclinical hypothyroidism, $336(0.3 \%)$ had overt hypothyroidism and 127215 (95.9\%) were euthyroid. Only $19(0.01 \%)$ subjects had T3 thyrotoxicosis. The details of the selection process of the study cohort are outlined in flow chart (figure 1). The baseline characteristics of the five groups are presented in the table 2. Patients with thyroid disorder were older and less often men (24\% vs 51\%). The distribution of women and men in each age group and different thyroid dysfunction groups are outlined in a table in supplementary material (online supplementary appendix $\mathrm{C}$ ).

\section{Heart rate}

The mean heart rate in subjects with both overt $(87 \pm 12$ beats $/ \mathrm{min})$ and subclinical hyperthyroidism $(76 \pm 14$ beats $/ \mathrm{min})$ was higher than the mean heart rate in euthyroid subjects ( $70 \pm 13$ beats/min, figure 2$)$, whereas subjects with overt hypothyroidism ( $68 \pm 12$ beats/ min) had slower mean heart rate than those with euthyroidism. For the association between thyroid dysfunction and heart rate, interactions with both age $(\mathrm{p}=0.009)$ and sex $(p<0.001)$ were identified. Among women, the higher 
Women

\begin{tabular}{|c|c|c|c|}
\hline & Estimate & $95 \% \mathrm{CI}$ & \\
\hline \multicolumn{4}{|l|}{$16.0-44.6$ years } \\
\hline Overt hyperthyroidism & 12.55 & {$[9.48 ; 15.61]$} & $\mapsto \bullet-1$ \\
\hline Subclinical hyperthyroidism & 2.29 & {$[-1.50 ; 6.08]$} & --1 \\
\hline Euthyroidism & Ref & & \\
\hline Subclinical hypothyroidism & 2.28 & {$[0.05 ; 4.50]$} & -1 \\
\hline Overt hypothyroidism & -9.00 & {$[-15.14 ;-2.85] \longmapsto-1$} & \\
\hline \multicolumn{4}{|l|}{$44.6-60.0$ years } \\
\hline Overt hyperthyroidism & 5.77 & {$[2.50 ; 9.04]$} & $\mapsto-1$ \\
\hline Subclinical hyperthyroidism & 4.40 & {$[1.53 ; 7.28]$} & $\mapsto=-1$ \\
\hline Euthyroidism & Ref & & \\
\hline Subclinical hypothyroidism & 0.38 & {$[-1.33 ; 2.09]$} & H \\
\hline Overt hypothyroidism & -7.81 & {$[-12.75 ;-2.88] \quad \longmapsto-1$} & \\
\hline \multicolumn{4}{|l|}{$60.0-102.7$ years } \\
\hline Overt hyperthyroidism & -0.20 & {$[-2.94 ; 2.55]$} & \\
\hline Subclinical hyperthyroidism & 0.13 & {$[-1.56 ; 1.82]$} & \\
\hline Euthyroidism & Ref & & \\
\hline Subclinical hypothyroidism & 1.56 & {$[0.21 ; 2.90]$} & - \\
\hline \multirow[t]{2}{*}{ Overt hypothyroidism } & 1.13 & {$[-2.93 ; 5.19]$} & $=-1$ \\
\hline & & $\begin{array}{cccc}1 & 1 & \\
-15 & -10 & -5 & 0 \\
& & \\
& & \text { Es }\end{array}$ & 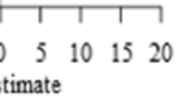 \\
\hline
\end{tabular}

Men

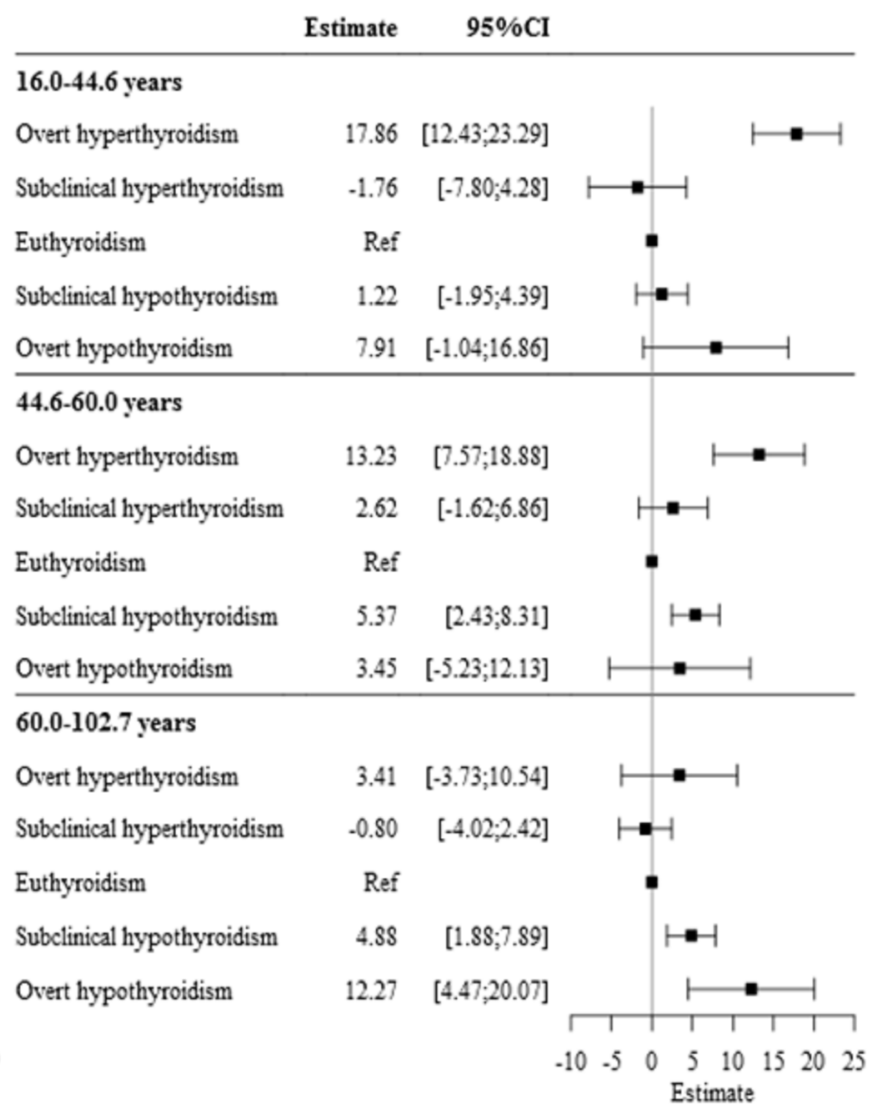

Figure 4 Changes in QTc interval with thyroid dysfunction by gender and age. Regression plots showing the changes in the QTc interval (ms) with thyroid disorders in comparison with the euthyroidism based on age groups and gender.

heart rate for overt hyperthyroidism and lower heart rate for overt hypothyroidism were less pronounced for patients of higher age (figure 3). Likewise, among men, the association between higher heart rate and overt hyperthyroidism was less pronounced in patients with higher age. Subclinical hyperthyroidism was also associated with higher heart rate across all thee age groups among women. For men, a similar trend was observed (figure 3).

\section{QTc interval}

In comparison with the euthyroid group ( $425 \pm 24 \mathrm{~ms})$, the heart rate corrected QTc interval (QTc Bazett) was prolonged in subjects with overt hyperthyroidism $(435 \pm 22$ $\mathrm{ms}, \mathrm{p}<0.05)$, subclinical hyperthyroidism $(431 \pm 24 \mathrm{~ms}$, $\mathrm{p}<0.05)$ and subclinical hypothyroidism $(431 \pm 24 \mathrm{~ms}$, $\mathrm{p}<0.05)$. Significant interactions with both age $(\mathrm{p}<0.001)$ and sex $(\mathrm{p}<0.001)$ were identified. For both sexes, overt hyperthyroidism was significantly associated with significantly prolonged QTc interval in the young (16-44.6 years) to middle-age (44.6-60 years) groups but not in the oldest subgroup (60-102.7 years; figure 4). Among women, overt hypothyroidism was significantly associated with a shorter QTc interval in the young to middle-age groups, whereas the association was insignificant for the oldest age group (figure 4). Among men, however, the QTc interval was longer in patients with both subclinical and overt hypothyroidism only in the oldest age group (figure 4).

\section{Low voltage}

Among the study groups, both subclinical and overt hypothyroidism were associated with low voltage. With increasing age, the observed associations were less pronounced ( $\mathrm{p}=0.0018$ for interaction) (figure 5).

\section{P-wave duration, PR interval and QRS duration}

In comparison with the P-wave duration in the euthyroid group $(108.7 \pm 12.6 \mathrm{~ms})$, the P-wave duration was shorter in patients with overt hyperthyroidism $(106.0 \pm 12.6 \mathrm{~ms}$, figure 2) by an estimate mean duration of $-2.2 \mathrm{~ms} \mathrm{(95 \%} \mathrm{CI}$ 1.4 to 3.1 ) in a multiple regression analysis (figure 6 ). The mean PR interval in the overt hypothyroidism (165 \pm 25$)$ was significantly longer in comparison with the euthyroid group ( $158 \pm 23 \mathrm{~ms}$, figure 2$)$ by an estimate mean duration of $6.61 \mathrm{~ms}$ (95\% CI 4.30 to $8.92 \mathrm{~ms}$ ) in a multivariate analysis (figure 6). Similarly, subclinical hypothyroidism was associated with longer PR interval by $1.5 \mathrm{~ms}(95 \% \mathrm{CI}$ $0.7-2.3 \mathrm{~ms}$ ). The overt hyperthyroid subjects had a shorter QRS duration $(88.5 \pm 9.6)$ in comparison with the euthyroid $(93.5 \pm 10.5 \mathrm{~ms}$ ) subjects (figure 2). However, no significant difference was observed in a multivariate analysis (figure 6). 


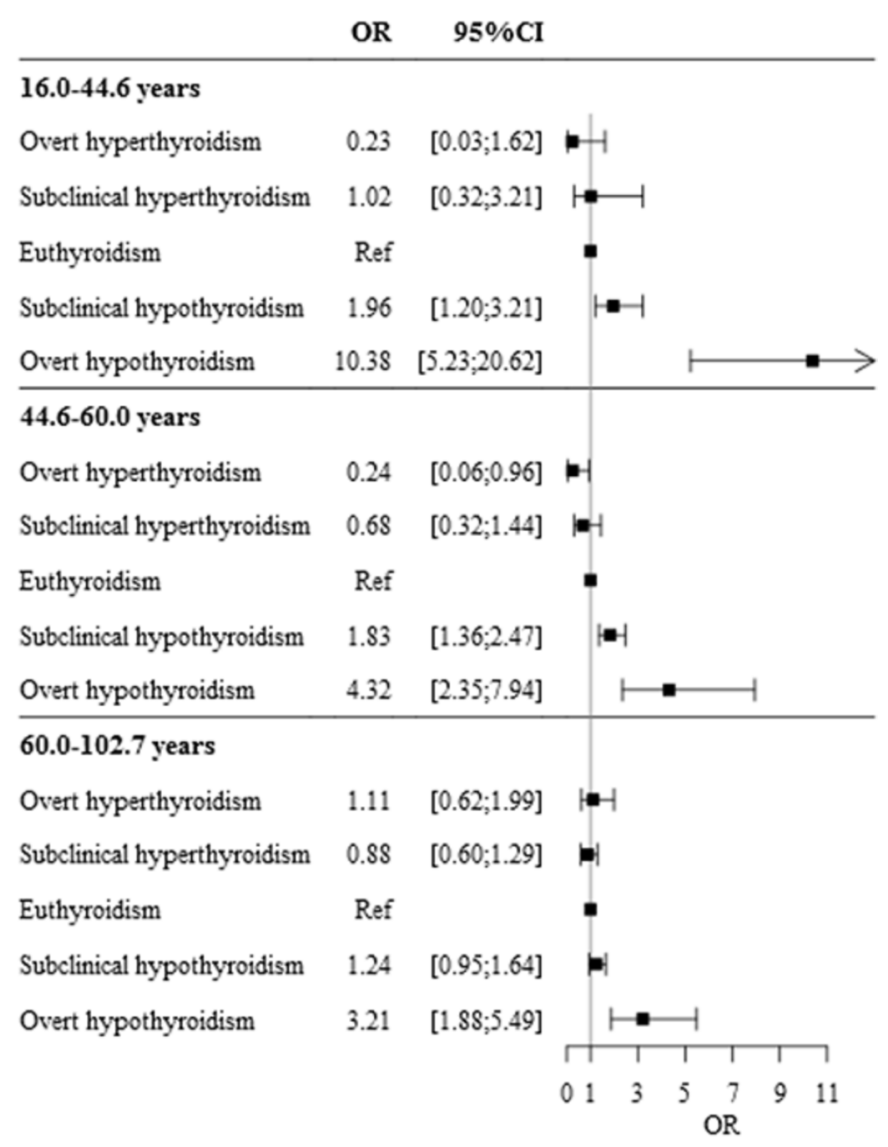

Figure 5 Risk of low voltage with thyroid dysfunction. Forest plot showing the risk for low-voltage on ECG with thyroid disorders in comparison with the euthyroid reference group after adjusting for age and gender.

\section{Additional analysis}

We performed a sensitivity analysis, in which individuals with known cardiac comorbidity and concomitant medical therapy that might influence the ECG parameters were excluded. In this sensitivity analysis, 100176 individuals were included, which corresponds to approximately $75 \%$ of the total study population. Overall, the results did not differ from our main findings (provided in online supplementary appendix D). Additional analyses for the association of TSH levels on heart rate and QTc interval are provided in online supplementary appendix E.

\section{DISCUSSION}

This large registry-based study demonstrates associations of both overt and subclinical thyroid dysfunction with a range of common ECG parameters such as heart rate, QTc interval, PR interval, QRS duration, P-wave duration and presence of low voltage that verifies some of the findings from previous studies in a larger cohort. ${ }^{1011} 141517$ The most novel finding of the current study is that the impact of thyroid dysfunction on heart rate, QTc interval and presence of low-voltage is lower with higher patient age. Moreover, women have significantly greater changes in heart rate and QTc interval than men. These findings

\section{P wave duration}
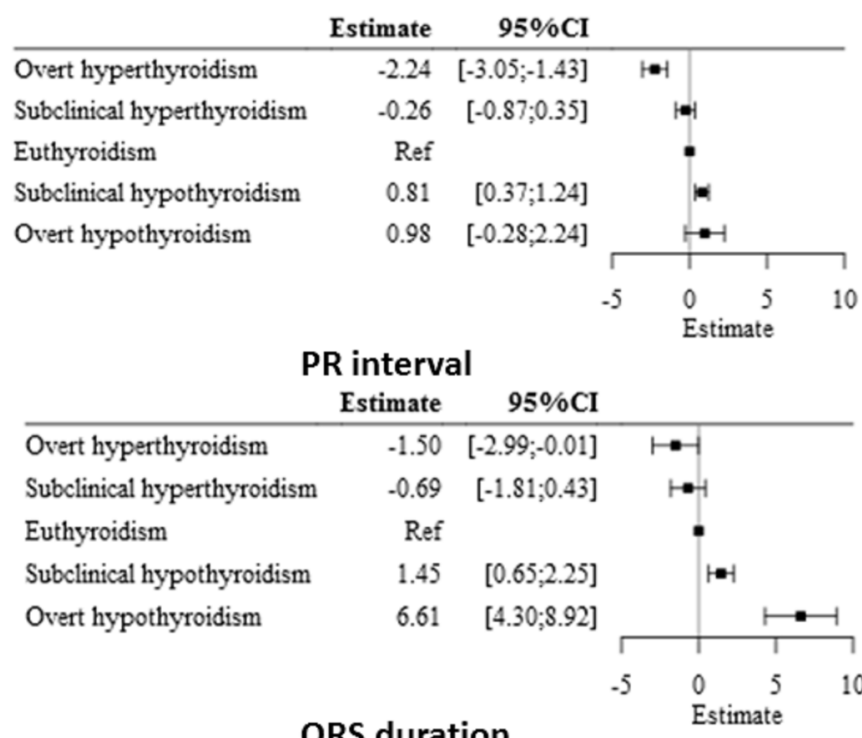

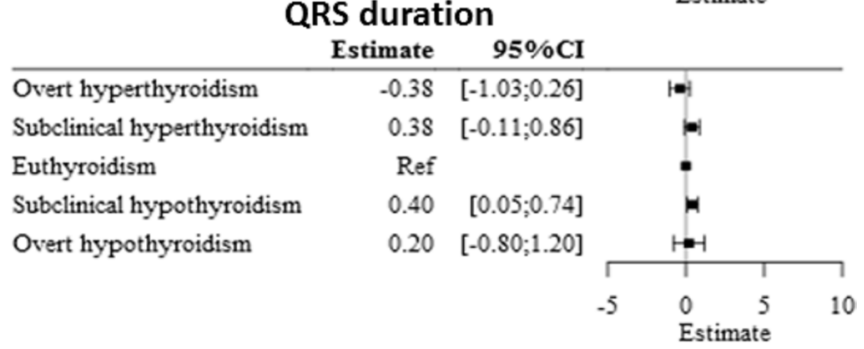

Figure 6 Changes in P-wave, PR interval and QRS duration according to thyroid dysfunction. Regression plots showing the changes in the P-wave duration (ms), PR interval (ms) and QRS duration ( $\mathrm{ms}$ ) with thyroid disorder in comparison to the euthyroid reference group adjusted for age and gender.

expand our existing knowledge on ECG changes associated with thyroid dysfunction.

Most of the previous studies have investigated the relationship of thyroid dysfunction with QTc interval as both prolonged and shorter QTc interval have been associated with sudden cardiac death and complex ventricular arrhythmias. $^{12} 23$ The general consensus from previous smaller studies is that both hyperthyroidism ${ }^{10162425}$ and hypothyroidism ${ }^{14152627}$ are associated with prolongation of the QTc interval. In the present study, hyperthyroidism was associated with prolonged QTc interval in younger to middle-aged subjects among both genders, but the association was weakened with age and was not present for older patients. Moreover, hypothyroidism was associated with both prolongation and shortening of QTc interval depending on the age and gender of the subjects. These findings indicate that the effect of thyroid disorder on the electrical conduction system of heart varies by gender and the thyroid hormonal influence on the heart decreases with age.

Previous studies have reported that hyperthyroidism is associated with increased heart rate while hypothyroidism leads to a slower heart rate. ${ }^{3}$ Increased heart rate has been associated with mortality and cardiovascular morbidity. ${ }^{28} 29$ The present study confirmed previous 
findings with overall higher and lower heart rates for patients with hyperthyroidism and hypothyroidism, respectively. In addition, we report that these findings differed according to different age groups like QTc interval, indicating that the thyroid hormonal influence on the heart decreases with age. Furthermore, the effect of hypothyroidism on heart rate was limited to women in our study.

The present study found an increased risk of low voltage in both subclinical and overt hypothyroidism. Although previous studies have demonstrated that overt hypothyroidism is associated with low voltage,$^{30}$ our study further extends the finding of increased risk of low voltage even in patients with subclinical hypothyroidism. This suggests that even mild thyroid hormone deficiency can affect the QRS voltage amplitude, which might be important given the fact that low voltage is associated with increased risk of mortality. ${ }^{31}$ A survey from the USA found that presence of low voltage on ECG in patients with no history of cardiovascular disease was associated with a two-fold increased risk of mortality in comparison with those without low voltage changes on ECG. ${ }^{31}$ The current study further demonstrates that with increasing age, the likelihood of presence of low-voltage on ECG is reduced in patients with hypothyroidism.

We consistently found that the influence of thyroid dysfunction on ECG changes was less pronounced in patients with higher age. One potential explanation could be that sensitivity of the electrical conduction system of the heart to changes in the thyroid hormone level is reduced with age. Another plausible explanation is that because of ECG changes due to prevalent age-related comorbidities, the changes due to thyroid dysfunction are not evident. This latter explanation is however not supported by our sensitivity analysis, in which patients with cardiac comorbidities and/or concomitant medical therapy that interact with ECG parameters were excluded, still the results were consistent with our main findings. In addition, our findings are also supported by recent studies demonstrating that thyroid dysfunction have no impact on cardiovascular outcomes and mortality in elderly populations. ${ }^{832}$

In the present study, we observed a shorter P-wave duration in hyperthyroidism and a longer PR interval in patients with hypothyroidism when adjusted for age, gender and heart rate in the adjusted models. Few smaller studies have investigated the association of thyroid hormones on PR interval and QRS duration with some conflicting results. ${ }^{27}{ }^{33}$ However, in our study, we did not observe any associations between the different thyroid conditions and changes in QRS duration. Changes in P-wave duration and PR interval have important implications as demonstrated by Nielsen $\mathrm{et} \mathrm{al}$, where both shorter and longer P-wave duration ${ }^{34}$ and PR interval ${ }^{22}$ were associated with increased risk for atrial fibrillation.

The association of TSH on heart rate and QTc interval in both sexes is limited to when TSH is depressed but not when it is elevated. Moreover, this association is predominantly observed among young and middle-aged subjects. This is partly in line with the main findings of our study observed among hyperthyroid dysfunction subgroups. However, changes in ECG parameters are not linearly correlated to increase in TSH which is likely related to changes in $\mathrm{T} 4$ as demonstrated by previous studies. $^{1025}$

\section{Implications}

Cardiomyocytes are well known to be affected by thyroid hormones with increased cardiac contractility and increased heart rate and risk of proarrhythmic effects. ${ }^{3}$ This study from a large real-life cohort presents the ECG changes in clinically relevant subgroups of thyroid dysfunctions that makes it easier for the study findings to apply in routine clinics. Moreover, it attempts to bridge the current abundant, but conflicting, knowledge on pathophysiological changes in ECG changes with thyroid dysfunction. Owing to large study population, it is revealed that there is a biological interaction of age and gender on the ECG changes associated with thyroid dysfunction. This indicates that ECG changes are not universal in each subgroup and are rather affected by the age and gender of the individual subject. Further research on the physiology behind this interaction will enrich our knowledge on the impact of thyroid dysfunction in cardiovascular morbidity and mortality. Moreover, the present study establishes that subclinical thyroid dysfunctions are also associated with important ECG changes that are known to be of prognostic importance. ${ }^{122} 3134$ Further studies focusing on the prognostic implication of these ECG changes in subclinical thyroid dysfunction would be clinically relevant.

\section{Limitations}

Despite being a large study cohort, our study has some important limitations. Since this is an observational study, it is not possible to draw direct conclusions on causality regarding the findings. The study patients were referred to TFT and an ECG recording by their general practitioner based on their discretion, and there were no uniform selection criteria for why the patients received these diagnostic tests, because of this selection bias cannot be ruled out that is, the general practitioners would be prone to focus more on tachycardia or bradycardia in patients with thyroid dysfunction and therefore order more ECGs in these subjects. Because ECGs were recorded \pm 7 days of the TFTs, there is also the risk of reverse causation bias, for instance, due to a finding of tachycardia on the ECG, the general practitioner decided to refer for TFTs. Additionally, this study did not have access to other clinical parameters, such as body mass index, smoking status and blood pressure. However, in a sensitivity analysis, exclusion of cardiac comorbidity and concomitant medical therapy that might influence the ECG pattern did not change the conclusions from the main findings. The greater Copenhagen area consists mainly of Caucasian people, and for that reason, extrapolation to other ethnic groups should 
be done carefully. Lastly, the size of the sample implies a possibility of type I error requiring a careful interpretation of the results from a clinical point of view.

\section{CONCLUSION}

Changes in ECG parameters particularly heart rate, QTc duration and low voltage were less pronounced in older patients with thyroid dysfunction relative to younger counterparts. Patients with both overt and subclinical thyroid dysfunctions were associated with significant changes in several ECG parameters including heart rate, QTc duration, P-wave duration, PR interval and low voltage.

\author{
Author affiliations \\ ${ }^{1}$ Department of Cardiology, Aalborg Universitetshospital, Aalborg, Denmark \\ ${ }^{2}$ Health Science and Technology, Aalborg University, Aalborg, Denmark \\ ${ }^{3}$ Department of Endocrinology, Herlev Hospital, Herlev, Denmark \\ ${ }^{4}$ Unit of Epidemiology and Biostatistics, Aalborg University Hospital, Aalborg, \\ Denmark \\ ${ }^{5}$ Department of Internal Medicine, Regionshospital Nordjylland, Hjorring, Nordjylland, \\ Denmark \\ ${ }^{6}$ Internal Medicine, Zealand University Hospital, Koge, Denmark \\ ${ }^{7}$ University of Michigan, Ann Arbor, USA \\ ${ }^{8}$ Nordsjaellands Hospital, Hillerod, Denmark \\ ${ }^{9}$ Department of Cardiology, Rigshospitalet, Kobenhavn, Denmark \\ ${ }^{10}$ Department of Cardiology, Aalborg University Hospital, Aalborg, Denmark \\ ${ }^{11}$ Department of Psychiatry, Amager Hospital, Kobenhavn, Denmark \\ ${ }^{12}$ Faculty of Health and Medical Science, Copenhagen University, Copenhagen, \\ Denmark \\ ${ }^{13}$ Department of Cardiology, Zealand University Hospital, Koge, Denmark \\ ${ }^{14}$ Department of Epidemiology and Biostatistics, Aalborg University Hospital, \\ Aalborg, Denmark \\ ${ }^{15}$ Department of Clinical Epidemiology, Aalborg University Hospital, Aalborg, \\ Denmark
}

Contributors The study was designed by BT, SMH, KK, CS, JF, MK, CG, CT-P, GHG and PS. The acquisition of the ECG along with other data were performed by $C G$, CT-P, AGH, JBN, A-MSO, AHP and CBC. Most analyses were performed by SMH, $\mathrm{KK}$ and BT. The initial manuscript draft was written by BT. All authors contributed significantly in the interpretation of the data and critical revisions of manuscript versions. All authors have approved the final version of the manuscript.

Funding The authors have not declared a specific grant for this research from any funding agency in the public, commercial or not-for-profit sectors.

Competing interests KK reports having received research grants from the Laerdal Foundation and speaker's honoraria from Novartis. AGH reports being an employee of Novo Nordisk. PS has received consultant fees from Biotronik, speaker fees from GE HealthCare and research grants from Biotronik, GE Health Care, Bayer and EBR systems. GHG reports research grants from Bayer, Boehringer Ingelheim, Pfizer, Bristol Myers Squibb and AstraZeneca. CT-P reports speaker honoraria and study grants from Bayer and a study grant from Biotronik. SMH reports receiving support from the Danish Foundation Trygfonden and the Danish Heart foundation. Other authors have nothing to declare.

Ethics approval The study was approved by the Danish Data Protection Agency (Journal number 2008-58-0028, internal reference RN-2016-3). This study involved no active patient participation. Consequently, no approval from an ethics committee was required.

Provenance and peer review Not commissioned; externally peer reviewed.

Data sharing statement No additional data available.

Open access This is an open access article distributed in accordance with the Creative Commons Attribution Non Commercial (CC BY-NC 4.0) license, which permits others to distribute, remix, adapt, build upon this work non-commercially, and license their derivative works on different terms, provided the original work is properly cited, appropriate credit is given, any changes made indicated, and the use is non-commercial. See: http://creativecommons.org/licenses/by-nc/4.0/.

\section{REFERENCES}

1. Hollowell JG, Staehling NW, Flanders WD, et al. Serum TSH, T(4), and thyroid antibodies in the United States population (1988 to 1994): National Health and Nutrition Examination Survey (NHANES III). J Clin Endocrinol Metab 2002;87:489-99.

2. Knudsen N, Jorgensen T, Rasmussen S, et al. The prevalence of thyroid dysfunction in a population with borderline iodine deficiency. Clin Endocrinol 1999;51:361-7.

3. Klein I, Danzi S. Thyroid Disease and the Heart. Curr Probl Cardiol 2016;41:65-92.

4. Selmer C, Olesen JB, Hansen ML, et al. The spectrum of thyroid disease and risk of new onset atrial fibrillation: a large population cohort study. BMJ 2012;345:e7895

5. Selmer C, Olesen JB, Hansen ML, et al. Subclinical and overt thyroid dysfunction and risk of all-cause mortality and cardiovascular events: a large population study. J Clin Endocrinol Metab 2014;99:2372-82.

6. Parle JV, Maisonneuve P, Sheppard MC, et al. Prediction of allcause and cardiovascular mortality in elderly people from one low serum thyrotropin result: a 10-year cohort study. Lancet 2001;358:861-5.

7. Rodondi N, Bauer DC, Cappola AR, et al. Subclinical thyroid dysfunction, cardiac function, and the risk of heart failure. The Cardiovascular Health study. J Am Coll Cardiol 2008;52:1152-9.

8. Cappola AR, Fried LP, Arnold AM, et al. Thyroid status, cardiovascular risk, and mortality in older adults. JAMA 2006;295:1033-41.

9. Dörr M, Empen K, Robinson DM, et al. The association of thyroid function with carotid artery plaque burden and strokes in a population-based sample from a previously iodine-deficient area. Eur $J$ Endocrinol 2008;159:145-52.

10. Zhang Y, Post WS, Cheng A, et al. Thyroid hormones and electrocardiographic parameters: findings from the third national health and nutrition examination survey. PLoS One 2013;8:e59489.

11. Tribulova N, Knezl V, Shainberg A, et al. Thyroid hormones and cardiac arrhythmias. Vascul Pharmacol 2010;52(3-4):102-12.

12. Nielsen JB, Graff C, Rasmussen PV, et al. Risk prediction of cardiovascular death based on the QTc interval: evaluating age and gender differences in a large primary care population. Eur Heart $J$ 2014;35:1335-44.

13. Bachmann TN, Skov MW, Rasmussen PV, et al. Electrocardiographic Tpeak-Tend interval and risk of cardiovascular morbidity and mortality: Results from the Copenhagen ECG study. Heart Rhythm 2016;13:915-24.

14. Osborn LA, Skipper B, Arellano I, et al. Results of resting and ambulatory electrocardiograms in patients with hypothyroidism and after return to euthyroid status. Heart Dis 1999;1:8-11.

15. Sarma JS, Venkataraman K, Nicod P, et al. Circadian rhythmicity of rate-normalized QT interval in hypothyroidism and its significance for development of class III antiarrhythmic agents. Am J Cardiol 1990;66:959-63.

16. Colzani RM, Emdin M, Conforti F, et al. Hyperthyroidism is associated with lengthening of ventricular repolarization. Clin Endocrinol 2001;55:27-32.

17. Dörr M, Ruppert J, Robinson DM, et al. The relation of thyroid function and ventricular repolarization: decreased serum thyrotropin levels are associated with short rate-adjusted QT intervals. J Clin Endocrinol Metab 2006;91:4938-42.

18. Lynge E, Sandegaard JL, Rebolj M. The Danish National Patient Register. Scand J Public Health 2011;39(7 Suppl):30-3.

19. Thygesen SK, Christiansen CF, Christensen S, et al. The predictive value of ICD-10 diagnostic coding used to assess Charlson comorbidity index conditions in the population-based Danish National Registry of Patients. BMC Med Res Methodol 2011;11:83.

20. Kildemoes HW, Sørensen HT, Hallas J. The danish national prescription registry. Scand J Public Health 2011;39(7 Suppl):38-41.

21. Nielsen JB, Graff C, Pietersen A, et al. J-shaped association between QTC interval duration and the risk of atrial fibrillation: results from the Copenhagen ECG study. J Am Coll Cardiol 2013;61:2557-64.

22. Nielsen JB, Pietersen A, Graff C, et al. Risk of atrial fibrillation as a function of the electrocardiographic PR interval: results from the Copenhagen ECG Study. Heart Rhythm 2013;10:1249-56.

23. Straus SM, Kors JA, De Bruin ML, et al. Prolonged QTc interval and risk of sudden cardiac death in a population of older adults. $J \mathrm{Am}$ Coll Cardiol 2006;47:362-7.

24. Lee YS, Choi JW, Bae EJ, et al. The corrected QT (QTC) prolongation in hyperthyroidism and the association of thyroid hormone with the QTc interval. Korean J Pediatr 2015;58:263-6.

25. van Noord C, van der Deure WM, Sturkenboom MC, et al. High free thyroxine levels are associated with QTc prolongation in males. $J$ Endocrinol 2008;198:253-60. 
26. Owecki M, Michalak A, Nikisch E, et al. Prolonged ventricular repolarization measured by corrected QT interval (QTc) in subclinical hyperthyroidism. Horm Metab Res 2006;38:44-7.

27. Kweon KH, Park BH, Cho CG. The effects of L-thyroxine treatment on QT dispersion in primary hypothyroidism. J Korean Med Sci 2007;22:114-6.

28. Woodward M, Webster R, Murakami Y, et al. The association between resting heart rate, cardiovascular disease and mortality: evidence from 112,680 men and women in 12 cohorts. Eur J Prev Cardiol 2014;21:719-26.

29. Aune D, Sen A, ó'Hartaigh B, et al. Resting heart rate and the risk of cardiovascular disease, total cancer, and all-cause mortality - A systematic review and dose-response meta-analysis of prospective studies. Nutr Metab Cardiovasc Dis 2017;27:504-17.
30. Tajiri J, Morita M, Higashi K, et al. The cause of low voltage QRS complex in primary hypothyroidism. Pericardial effusion or thyroid hormone deficiency? Jpn Heart J 1985;26:539-47.

31. Usoro AO, Bradford N, Shah AJ, et al. Risk of mortality in individuals with low QRS voltage and free of cardiovascular disease. Am J Cardiol 2014;113:1514-7.

32. Kalra S, Williams A, Whitaker R, et al. Subclinical thyroid dysfunction does not affect one-year mortality in elderly patients after hip fracture: a prospective longitudinal study. Injury 2010;41:385-7.

33. Venkatesh N, Lynch JJ, Uprichard AC, et al. Hypothyroidism renders protection against lethal ventricular arrhythmias in a conscious canine model of sudden death. J Cardiovasc Pharmacol 1991:18:703-10.

34. Nielsen JB, Kühl JT, Pietersen A, et al. P-wave duration and the risk of atrial fibrillation: Results from the Copenhagen ECG Study. Heart Rhythm 2015;12:1887-95. 